\title{
Automatic detection of small PIT-tagged animals using wildlife crossings
}

\author{
Guillaume Testud ${ }^{1,4}$, Alan Vergnes ${ }^{2}$, Philippe Cordier ${ }^{3}$, Dorothée Labarraque ${ }^{4}$ and Claude Miaud ${ }^{1 *}$ (I)
}

\begin{abstract}
Background: Mitigating the effect of linear transport infrastructure (LTI) on fauna is a crucial issue in road ecology. Wildlife crossing structures (tunnels or overpasses) are one solution that has been implemented to restore habitat connectivity and reduce wildlife mortality. Evaluating how these crossings function for small wildlife has often been recommended but, mainly due to technical limitations, is not often conducted in practice or only as short-term monitoring (less than 1 year). In this study, we developed and tested an automated device that records the detailed behaviour of animals when using wild life tunnels. The method is based on marking and detecting individuals with RFID (radio-frequency identification) tags and allows small animals to be tracked. Composed of four antennas (detectors) placed at roughly $2 \mathrm{~m}$ intervals, the system was tested in a tunnel in northern France in the summer of 2017. One species of amphibian (the toad Bufo spinosus, $n=13$ ) and two carabids (the ground beetles Carabus coriaceus and Carabus nemoralis, respectively, $n=3$ and $n=4$ ), marked beforehand with PIT (passive integrated transponder) tags, were recorded when they crossed these detectors. This allowed individual trajectories, including crossing speed, to be estimated.
\end{abstract}

Results: We found that 12 of the 13 toads and 3 of the 7 ground beetles successfully crossed the entire wildlife passage of $7 \mathrm{~m}$ long. The detection rate of each detector varied from 8.33 to $100 \%$, with a mean of $52.08 \%$. All individuals were recorded by at least one detector. We observed high variability in the crossing characteristics of toads (mean transit duration $=41 \mathrm{~min}$ and $15 \mathrm{~s} \pm 25 \mathrm{~min}$ ) and ground beetles (6 $\mathrm{h} 11 \mathrm{~min} \pm 3 \mathrm{~h} 30 \mathrm{~min}$ ). The system provided information on precise trajectories (e.g., crossing speed, U-turns, distance travelled in the tunnel, proportion of individuals reaching the exit, etc.) for each individual, in a context of tunnel crossing.

Conclusion: The system allowed us to record small animal behaviour in the context of tunnel crossing in which other types of tracking (e.g. radio-tracking) or detection (e.g. camera traps) are not effective. It also opens the possibility for a range of experiments that would contribute to a better understanding of the behaviour of small animals in tunnels, allowing a comparison of tunnel characteristics (such as size, building material, substrate, etc.) with the aim of increasing wildlife use of the tunnel and proposing guidelines for the construction and maintenance of these mitigation measures.

Keywords: RFID, PIT tag, Amphibian, Ground beetle, Mitigation evaluation, Linear transport infrastructure, Habitat fragmentation, Movement

\footnotetext{
*Correspondence: claude.miaud@cefe.cnrs.fr

${ }^{1}$ UMR 5175 CEFE, EPHE, CNRS, UM, Univ P. Valery, SupAgro, IRD, INRA,

Biogéographie et Écologie des Vertébrés, PSL Research University,

34293 Montpellier, France

Full list of author information is available at the end of the article
} 


\section{Background}

The negative effects of linear transport infrastructure (LTI) on ground-dwelling fauna $[1,2]$ such as amphibians [3-5] and some ground beetles [6-10] are well documented. Direct mortality, habitat destruction, and fragmentation (due to a barrier effect) are the most commonly observed effects, with one study highlighting a success rate of only $3 \%$ in ground beetles crossing a railway line [11, 12]. Mitigation measures aim to restore crucial conservation aspects such as habitat connectivity and reducing mortality, both of which are important issues in road ecology. Of these measures, wildlife crossings (overpasses above or underpasses below an LTI) have been widely implemented. These are designed to guide animals to the entrance of the crossing and prevent their access to the LTI $[1,13]$. Despite the high cost of these structures, their efficacy is rarely evaluated in practice [7]. Due to technical limitations, this is particularly the case for small wildlife such as amphibians and ground beetles $[14,15]$.

Several methods are available for monitoring the use of wildlife crossings by amphibians and ground beetles. For example, individuals can be caught at the entrance of the tunnel by pitfall traps, and then counted and/or marked. Monitoring at the exit can then provide information about the transit time within the tunnel. Radio-tracking allows an animal's movements before entering and when leaving a tunnel to be recorded (e.g., [16]).

However, for small animals, the size of the emitter and battery limits the use of radio-tracking [15], making it impossible to record successive positions within the tunnel during the crossing. Camera traps are widely use to monitor tunnels use (reviewed in [17] and [18]), and the increasing quality of the recorded pictures/videos and automatic detection devices allow their use for small ectothermic organisms [19-21]. Moreover, the precise trajectory of amphibian during short-term movements can be recording thanks to fluorescent pigments [22, 23].

In this study, we experimented with the use of RFID (radio-frequency identification) technology to study the crossing of a wildlife tunnel by small vertebrates (amphibians) and ground-dwelling insects (ground beetles). Our method involved marking individuals with PIT (passive integrated transponder) tags, in which an alphanumeric code is stored to identify the individual. While this marking technique is widely used in amphibians (e.g., newts, salamanders and frogs [24-26], it is more scarce for ground-dwelling insects, though it has been used for mole crickets [27] and weevil beetles [28]. To our knowledge, no previous studies using RFID on ground beetles have been published. With this method, an array of detectors can be used to provide fine-scale movement data, as has been shown with fish [29], lizards [30] and voles [31, 32]. In the context of wildlife passage evaluation, studies have used PIT tags associated with an array of detectors to monitor a fish pass (e.g., [33, 34]). The system has also been used for terrestrial animals: for example, to detect the passage of tortoises and snakes in tunnels under roadways [16, 35]. It was also used for tracking salamanders migrating on land [14]. However, to our knowledge, it has never previously been used to monitor amphibian or insect movements in wildlife crossings.

To address this gap, we tested an RFID system composed of four detectors placed in a wildlife tunnel to record the behaviour of small animals crossing it. One species of amphibian (Bufo spinosus) and two species of flightless ground beetles (Carabus coriaceus and Carabus nemoralis) were marked and released at the entrance of the tunnel to test the system. The advantages and drawbacks of the method are discussed, as well as recommendations to allow its generalized use in the field.

\section{Methods}

\section{Design of the monitoring system}

The structure of the tracking system was almost the same for the two experiments (one with toads and one with carabids). The crossing was an existing tunnel (7-m long, 1-m wide and 1-m high) (Fig. 1) composed of scuppers (drainpipes) that lay under a road. At each end, $50-\mathrm{cm}$ high fences were built to prevent the animals from escaping from the tunnel. A thin layer of soil (less than 8-cm deep) lined the base of the tunnel.

Four detectors were set up within the tunnel. The detectors were Biolog-id outdoor antennas $(100 \times 8.5 \times 2.5 \mathrm{~cm})$ connected to an electronic control unit or 'reader' (which multiplexed the four $134.2 \mathrm{kHz}$ antennas, each protected in a waterproof box). Each antenna included an autotuning function and a rechargeable power battery. The detection distance of an antenna was $3 \mathrm{~cm}$, with models of PIT tag and detectors used. The reader, also protected by a waterproof box, had a memory capacity of about 1000 recordings and an interface that worked with Windows software. The minimum time between the detection of two successive PIT tags was $70 \mathrm{~ms}$.

For the toad experiment, the detectors were positioned on the ground of the tunnel. The first detector was positioned at a distance of $0.5 \mathrm{~m}$ from the entrance, the second at $2.5 \mathrm{~m}$, the third at $4.5 \mathrm{~m}$ and the last at $6.5 \mathrm{~m}$ (or $0.5 \mathrm{~m}$ from the exit). The distance between the first and last detector was thus about $6 \mathrm{~m}$ (Fig. 1). Preliminary observations showed that the toads easily crossed the detectors (thickness of $2.5 \mathrm{~cm}$ ) when moving in the tunnel.

In the ground beetle experiment, the first detector was located $1 \mathrm{~m}$ from the entrance, the second at $3 \mathrm{~m}$, the third at $5 \mathrm{~m}$ and the last at $7 \mathrm{~m}$, i.e., at the tunnel exit. The detectors were buried in the soil present in the tunnel, 


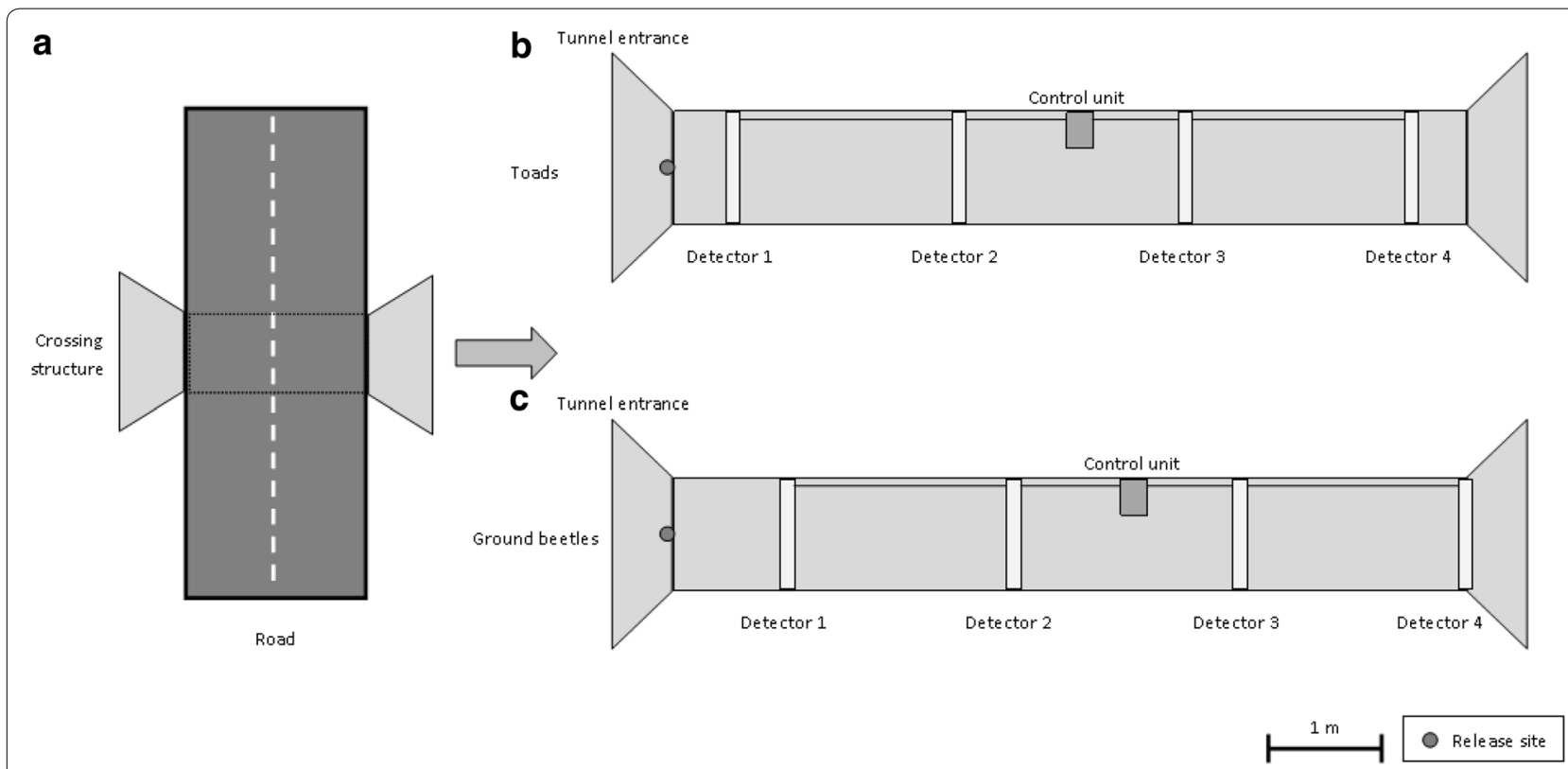

Fig. 1 Design of the experimental system. a A schematic view of the tunnel below the road. $\mathbf{b}$ Implementation of the RFID detection device (four antennas and a control unit, or 'reader') positioned along the tunnel for toads. The animals were released at the entrance of the tunnel. $\mathbf{c}$ Implementation of the RFID detection device (four antennas and a control unit, or 'reader') positioned along the tunnel for ground beetles. The animals were released at the entrance of the tunnel

allowing the beetles to cross them when moving in the tunnel.

The transponders (PIT tags, $1.4 \times 8 \mathrm{~mm}$, weight $34.2 \mathrm{mg}$ ) (Biolog-Tiny REF 10268 [R02-0717]) used to mark the toads and insects were electronic chips packaged in a 'biocompatible' glass ampoule that meets international standards for animal identification (ISO 11784/11785).

\section{Amphibian capture and tracking}

The study area was located in the region of Pays-de-laLoire in northwestern France. Within this area, at the beginning of March 2017, 13 adult common toads (Bufo spinosus) were collected by hand on rainy or foggy nights while they were migrating to aquatic breeding sites. The toads were measured: the mean snout-vent length was $6 \pm 1 \mathrm{~cm}$. They were then kept in opaque plastic tanks $(0.80 \times 0.40 \times 0.25 \mathrm{~m})$ until the beginning of the experiment. The holding duration was up to 1 week to capture enough individuals for the experiment and release them when the meteorological conditions were favourable for amphibian activity. Each individual was implanted with a PIT tag using an injector with a $1.75 \mathrm{~mm}$ diameter needle.

The release of the marked toads in the experimental device started at 9:30 p.m. (i.e., after the sunset), as these toads are active at night in this region and during this season. For the release, a marked toad was kept in an individual $15 \times 15 \times 15 \mathrm{~cm}$ plastic tank deposited at the entrance of the tunnel for a 5-min period. Each toad was released successively at the entrance of the tunnel every $5 \mathrm{~min}$. At the exit of the tunnel, the individuals were caught, identified and stored in individual plastic tanks. They were released at the exact place of capture the day after the experiment.

\section{Ground beetle capture and tracking}

Between 17 and 21 June 2017 in a forest close to the study area, 7 adult ground beetles-Carabus (Archicarabus) nemoralis (O.F. Müller, 1764) $(n=3)$ and Carabus (Procustes) coriaceus coriaceus (L. 1758) $(n=4)$-were captured with pitfall traps. The species $C$. nemoralis is a carabid of 18-28 $\mathrm{mm}$ [36] with a weight ranging from 0.360 to $0.605 \mathrm{~g}$ [37]. The species C. coriaceus is one of the largest carabids in Europe, varying in size from 33 to $40 \mathrm{~mm}$ [38], and in weight between 1.195 and $1.878 \mathrm{~g}$ [39]. Neither species has functional wings: their active dispersal and movements are strictly ground dwelling [40]. These species are widespread in Europe, but prefer deciduous and mixed forests [38].

Individuals were brought to the laboratory, identified by sex and tagged. The tag was glued to the end of a $30-\mathrm{mm}$ length of fishing line $(0.260 \mathrm{~mm}$ in diameter, Daiwa Sports Ltd, Wishaw, UK), and the line was then glued to the beetle's elytra (cyanoacrylate glue was used) (Fig. 2). A short adhesive strip (i.e., band aid) was glued on top to 


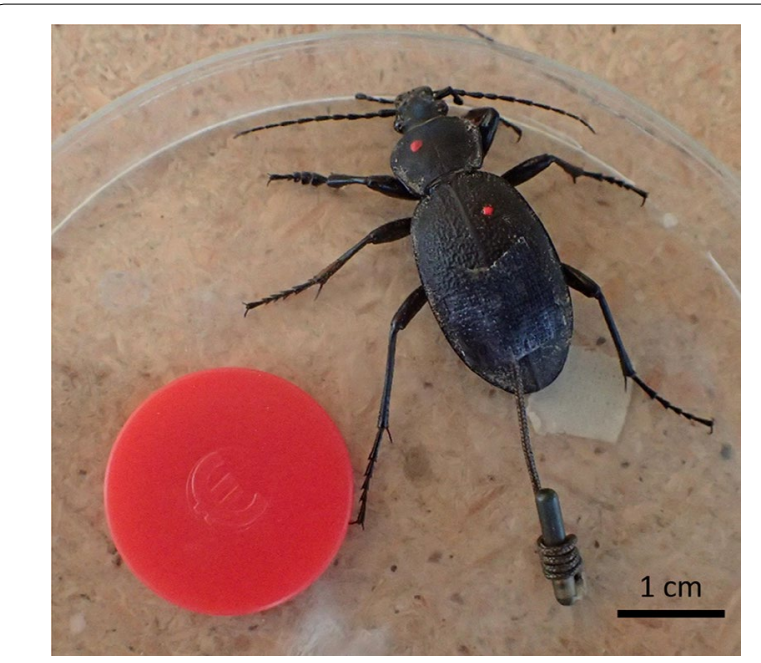

Fig. 2 A Carabus coriaceus ground beetle marked with a PIT tag. The tag was glued to the end of a 30-mm length of fishing line, and then glued to the insect's elytra

consolidate the fixation of the fishing line on the beetle's back. Finally, a spot was made on the insect elytra using a paint marker [41] so we could identify marked individuals in case they lost their RFID tag. The overall tagging system weighed around $0.120 \mathrm{~g}$, which is less than $30 \%$ of the body mass of these species (19.83-33.33\% of the body weight of C. nemoralis and 6.38-10.05\% of C. coriaceus [39],respectively). Tagged individuals were fed ad libitum and stored $24 \mathrm{~h}$ at $9{ }^{\circ} \mathrm{C}$ until release in the experimental device.

The release in the experimental device followed the method described for toads. As both beetle species are mainly crepuscular and nocturnal [38], release began from dusk (9:26 p.m.) on 22 June 2017 and movements were detected until 9:00 a.m. on 23 June 2017. The recaptured individuals were released at the place of capture the day after the experiment.

\section{Analysis of movements}

For each toad, the time of its entrance in and exit from the tunnel was recorded using direct observation. This allowed the calculation of the mean crossing speed. The detection of the marked individuals by the different successive antennas allowed building trajectories in the tunnel.

For each ground beetle, the time of entrance was known through direct observation (i.e., time of release). Due to their small size, nocturnal conditions and low speed traversal limited, direct observation of beetle's exit from the tunnel was difficult to conduct. Therefore, detection by detector 4 was considered the beetle's exit, completed by a visual inspection of the tunnel the day after the release to check for marked individuals that have crossed detector 4 and may have stayed in the end of the tunnel.

\section{Results}

\section{Tunnel crossing by toads}

Of the 13 released toads, 12 completely crossed the tunnel, while one made a U-turn and was recaptured at the entrance after staying 120 min inside. It was detected only in detector 1 twice, 3 and $8 \mathrm{~min}$ after its release. The toad detectability rate (i.e., the number of toads detected/the number of toads crossing the tunnel) varied between the detectors. The first detector recorded $8 / 12$ marked toads, the second $1 / 12$, the third $4 / 12$ and the last antenna 12/12 (Fig. 3).

The mean crossing time was $41 \mathrm{~min} 15 \mathrm{~s}( \pm 25 \mathrm{~min})$ at a speed of $0.0035 \mathrm{~m} \mathrm{~s}^{-1}\left( \pm 0.0017 \mathrm{~m} \mathrm{~s}^{-1}\right)$. One individual took twice as long to cross as the others (Fig. 3).

The path of three individuals (Fig. 4) illustrates the variability of toad movements within the tunnel: individual $\mathrm{T} 1$ had a rather constant speed, while individual T7 moved quickly in the first half of the tunnel, and then stayed more than an hour before moving again. Individual T9 moved slowly in the first half of the tunnel, and then accelerated in the second half.

\section{Tunnel crossing by ground beetles}

Of the 7 tracked individuals, 6 were at least detected once but only 3 managed to completely cross the tunnel. Three individuals were retrieved inside the tunnel at the end of the experiment and the undetected individual may have made a U-turn before detector 1 . This was achieved in an average time of $6 \mathrm{~h} 11 \mathrm{~min}( \pm 3 \mathrm{~h} 30 \mathrm{~min})$, corresponding to an average speed of $0.0003 \mathrm{~m} \mathrm{~s}^{-1}$. Individual G1 (a female $C$. nemoralis) crossed the tunnel in $10 \mathrm{~h} 29 \mathrm{~min}$ at a speed of $0.0001 \mathrm{~m} \mathrm{~s}^{-1}$, individual G2 (a male C. coriaceus) crossed in $6 \mathrm{~h} 13 \mathrm{~min}$ at a speed of $0.0003 \mathrm{~m} \mathrm{~s}^{-1}$ and individual G3 (a female C. nemoralis) in $3 \mathrm{~h} 12 \mathrm{~min}$ at a speed of $0.0006 \mathrm{~m} \mathrm{~s}^{-1}$.

The path of the three individuals in the tunnel was variable (Fig. 5): the speed of individual G1 was relatively constant, individual G2 turned back at one point before continuing on to the exit, and individual G3 went slowly in the first $3 \mathrm{~m}$ and then moved rapidly (4 $\mathrm{m}$ in less than $10 \mathrm{~min})$.

\section{Discussion}

Monitoring small animals in wildlife underpasses is subject to specific constraints. While radio-tracking (harmonic radar, VHF, GPS) transmitters or GPS tags can be used to record movements before entering or when leaving a tunnel, they do not allow tracking during the crossing. Another method that is widely used to monitor 


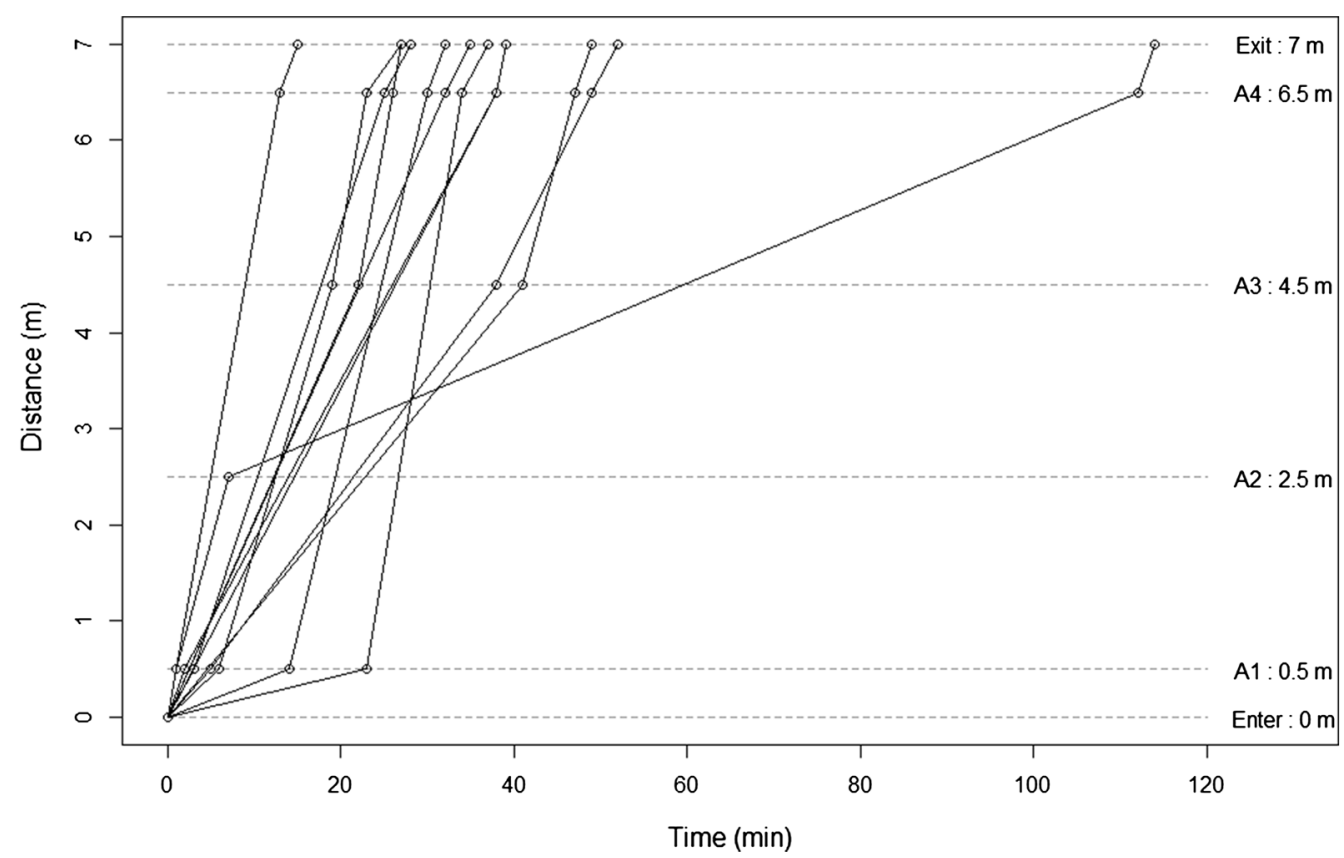

Fig. 3 The individual trajectories of 12 tagged toads that completely crossed the tunnel. The $x$-axis shows the time (in minutes) from release; the $y$-axis shows the distance travelled (in metres) from the entrance. Black line = observed toad trajectories; circles $=$ detection events (four detectors); horizontal dotted line $=$ detector' position in metres from the entrance

the use of tunnels is camera traps [17]. These have been used to record snakes and terrestrial turtles entering and leaving an ecopassage [16]. In another study, 58 salamanders were detected crossing four tunnels using cameras installed at the entrance, while 104 individuals were caught in pitfall traps at the exit of each tunnel [42]. For insects, monitoring with camera traps is still emerging [43]. The quality of the recorded pictures/videos and issues of detectability currently limit the effectiveness of camera traps for small organisms; however, technological developments may improve their use for small ectothermic animals [18-21]. The fine-scale movements of amphibians have been recording with individuals brushed with fluorescent pigments, leaving a detectable track on the ground [22]. This method was used to monitor in the context of wildlife underpass and it would be interesting to add it to the list of potential methods for their evaluation [23]. The main limitation could be the number of individuals that can be followed together and the need to access the tunnel-that is not always feasible-to follow the tracks left on the ground.

PIT tags associated with an array of detectors can be an effective alternative method when radio-tracking or direct detection (visual or with photos/videos) is not feasible. It has the advantages of PIT tag marking (low price, allowing many animals to be individually marked, plus marking longevity) and allows the automatic recording of marked individuals over long periods [35]. The price of the automatic recorder (antennas and reader) can limit its implementation in several tunnels, while simultaneous experiments are needed to test for, e.g., amphibian movements in tunnels of various characteristics. This method has been used to monitor fish migration (e.g., [34]) and the use of fish passes-in the latter study, the detectability of the tagged fish was tested experimentally and reached $100 \%$ [33]. For terrestrial organisms such as tortoises and snakes, the use of wildlife underpasses under roadways has been evaluated using antennas implanted at the entrance and exit of the tunnel $[16,35]$. In our study, we modified this to use several antennas within the tunnel; this allowed the recording of more precise trajectories and behaviour information.

Another challenge with monitoring small animals is marking the individuals. PIT tags, implanted in the body cavity, have been widely used in amphibians, and have been demonstrated as non-invasive (i.e., not affecting behaviour, body condition and/or survival) in newts (e.g., $[26,44])$, salamanders (e.g., [25, 45]) and frogs (e.g., [24, $46])$.

In invertebrates, PIT tags can also be implanted in the body cavity (e.g., in mole crickets, [27] or glued onto the external tegument (e.g., in weevil beetles, [28]). In our study, a PIT tag was glued onto a ground beetle's elytra (Fig. 2) and this stayed in place long enough for the 


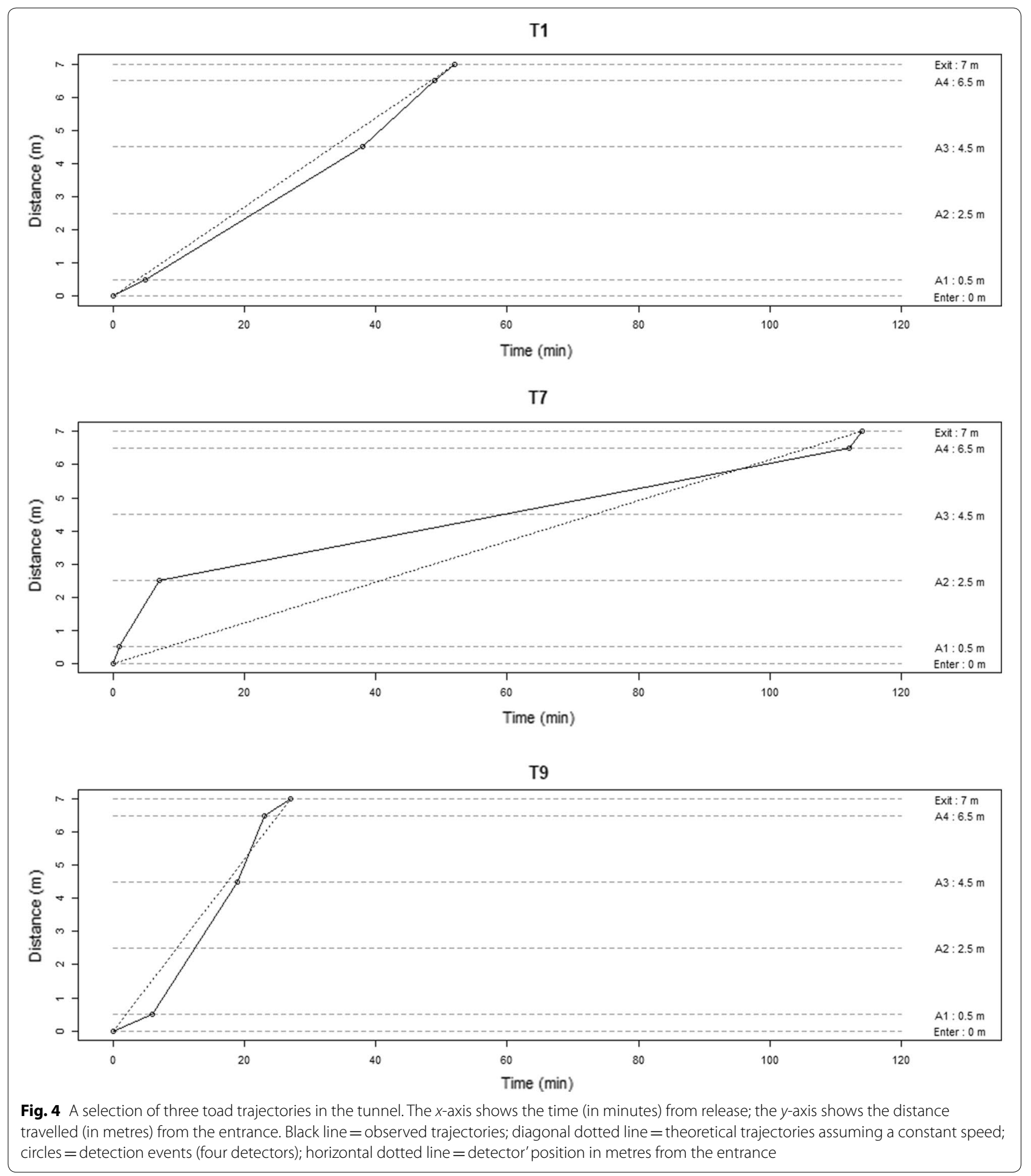

experiment (several hours). We consider that the tag did not alter the insect's behaviour.

However, using small PIT tags requires a short detection distance (e.g., less than $30 \mathrm{~mm}$ ), so the marked animals have to move close to the detector. The animal's locomotive characteristics can also alter its detection, for example, with jumping animals such as water frogs, etc. In our experiment with toads, the detection rate varies among the antenna while we know that all the individuals crossed the entire tunnel. Precise observation showed that some 


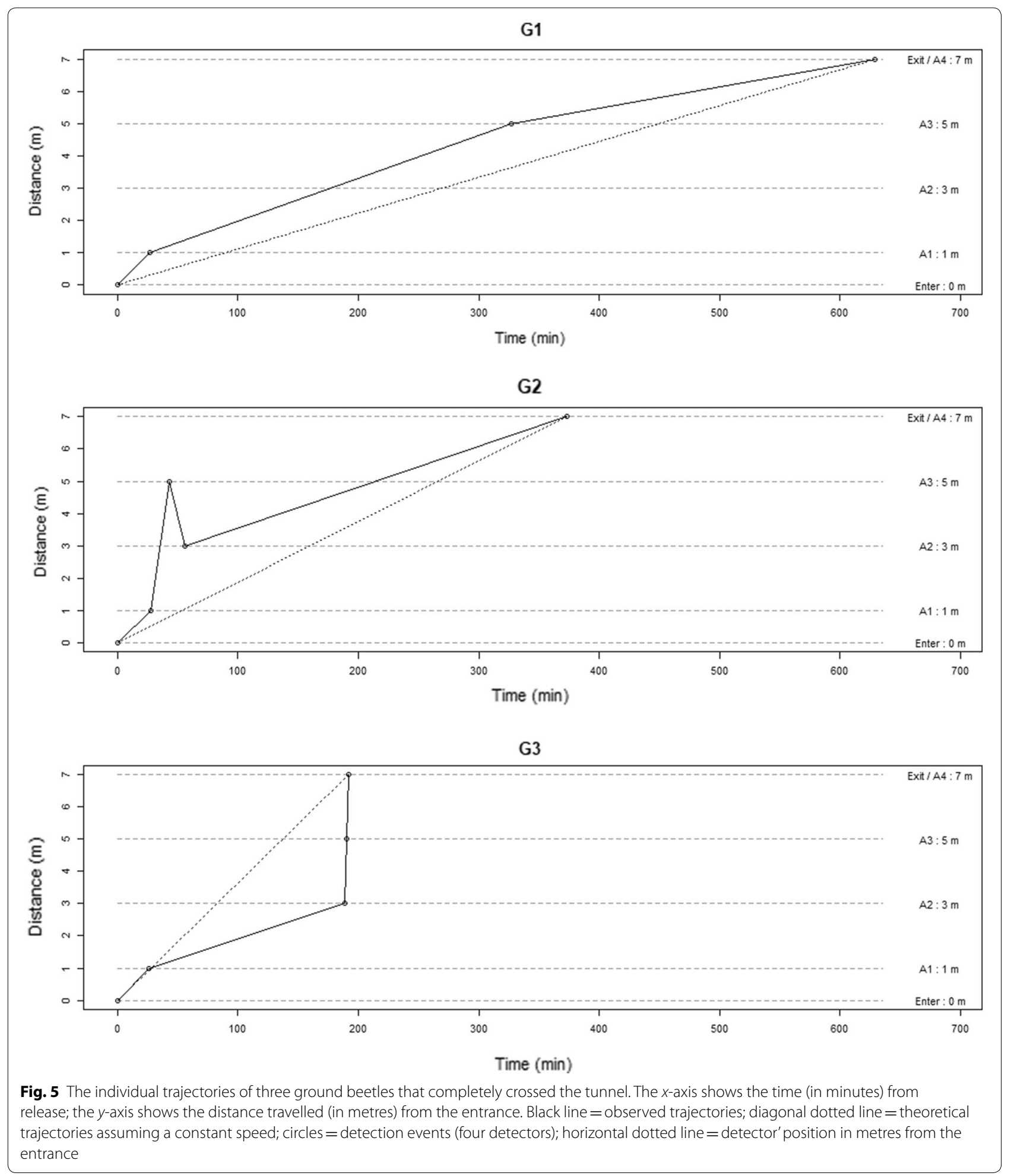

toads were able to avoid crossing the antenna by standing along the vertical sidewalls of the tunnel. Adding an object that prevents this behaviour makes it possible to obtain the crossing of all antennas in the following experiments.
Moreover, a minimum time has to elapse between the detection of two successive PIT tags $(70 \mathrm{~ms}$ in this study). In the case that two individuals simultaneously cross the antenna, only one individual will be recorded. 
And if one individual stays on the antenna, the detection of the other individuals will be inhibited [14]. These effects could explain the variation we observed in the detection rate between the four detectors.

\section{Conclusion}

In the context of wildlife crossings, while a large variety of animals can use them, evaluations tend to be species specific and mainly focus on large animals [13, 47, 48]. The system tested in this study, based on PIT tags, an array of detectors, and automatic recording, allows the detection of small animals (e.g., mammals, amphibians, reptiles and insects), and can provide precise behavioural information on how they react to tunnel characteristics. This system has the potential to enhance the ability to evaluate wildlife passages, resulting in more detailed information that is critical in improving their design [49]. Targeted experiments could also be implemented to test particular tunnel characteristics (e.g., length, substrate, luminosity, etc.) to guide the design of new wildlife crossings or modify existing ones.

\section{Acknowledgements}

We would like to thank A. Conan, E. Garcia, A. Legrand, Q. Le Petitcorps, Fiona Pujalte and Victor Vergnes Pujalte for their support in the field and D. Picard for student supervision. Many thanks to Elise Bradbury (elisebrad@gmail.com) for the text review and editing. This manuscript was improved by the reviewer's constructive comments.

\section{Authors' contributions}

GT, AV, PC, DL and CM designed the study. GT and AV conducted the experiments. GT, AV and CM conducted the analysis. All authors contributed to the writing. All authors read and approved the final manuscript.

\section{Funding}

Funding for this research programme was provided by the civil engineering construction firm Eiffage within the framework of the environmental observatory during the construction/exploitation of the LGV Bretagne-Pays-de-laLoire high-speed railway line. GT was directly funded by the French National Research and Technology Agency (ANRT-CIFRE), Grant No. 2017/0212 and the engineering firm Egis. The tags and detectors were provided by Eiffage, Egis and the Ecole Pratique des Hautes Etudes (EPHE).

\section{Availability of data and materials}

Not applicable.

\section{Ethics approval and consent to participate}

Authorization to catch common toads as a control was provided by the regional government of the study area (Regional Environment, Housing and Planning Agency of Sarthe, Mayenne and Ille-et-Vilaine, interprefectoral derogation from the prohibition to capture and transport specimens of protected animal species, 29 May 2017).

\section{Consent for publication}

Not applicable.

\section{Competing interests}

The authors declare that they have no competing interests. PC is a scientist in a private company specializing in RFID marking, including wildlife.

\section{Author details}

1 UMR 5175 CEFE, EPHE, CNRS, UM, Univ P. Valery, SupAgro, IRD, INRA, Biogéographie et Écologie des Vertébrés, PSL Research University, 34293 Montpellier, France. ${ }^{2}$ UMR 5175 CEFE, CNRS, EPHE, UM, SupAgro, IRD, INRA, Université Paul
Valery, 34293 Montpellier, France. ${ }^{3}$ Biolog-ld, 1 rue du Commandant Robert Malrait, 27303 Bernay, France. ${ }^{4}$ Egis Structures \& Environnement, 33-43, Avenue Georges Pompidou, 31130 Balma, France.

Received: 31 January 2019 Accepted: 3 October 2019 Published online: 22 October 2019

\section{References}

1. Jackson SD. Overview of transportation related wild life problems. In: proceedings of the international conference on wildlife ecology and transportation. FL-ER-69-98, Tallahassee: Florida Department of Transportation; 2000. p. 1-4

2. Rytwinski T, Soanes K, Jaeger JA, Fahrig L, Findlay CS, Houlahan J, et al. How effective is road mitigation at reducing road-kill? A meta-analysis. PLOS ONE. 2016;11(11):e0166941.

3. Andrews KM, Gibbons JW, Jochimsen DM, Mitchell J. Ecological effects of roads on amphibians and reptiles: a literature review. Herpetol Conserv. 2008;3:121-43.

4. Colino-Rabanal VJ, Lizana M. Herpetofauna and roads: a review. Basic Appl Herpetol. 2012;31(26):5-31.

5. Puky M. Amphibian road kills: a global perspective. In: Irwin CL, Garrett $P$, McDermott KP (eds) Proceedings of the 2005 international conference on ecology and transportation. Raleigh, NC: Center for Transportation and the Environment, North Carolina State University; 2005. p. 325-38.

6. Fahrig $L$, Rytwinski T. Effects of roads on animal abundance: an empirical review and synthesis. Ecol Soc. 2009;14(1):21.

7. van der Grift EA, van der Ree R, Fahrig L, Findlay CS, Houlahan J, Jaeger JA, et al. Evaluating the effectiveness of road mitigation measures. Biodivers Conserv. 2013;22(2):425-48.

8. Koivula MJ, Vermeulen HJW. Highways and forest fragmentationeffects on carabid beetles (Coleoptera, Carabidae). Landsc Ecol. 2005;20(8):911-26.

9. Muñoz PT, Torres FP, Megías AG. Effects of roads on insects: a review. Biodivers Conserv. 2015;24(3):659-82.

10. Niemelä J. Carabid beetles (Coleoptera: Carabidae) and habitat fragmentation: a review. EJE. 2013;98(2):127-32.

11. Forman RTT, Alexander LE. Roads and their major ecological effects. Annu Rev Ecol Syst. 1998;29(1):207-31.

12. Mader HJ, Schell C, Kornacker P. Linear barriers to arthropod movements in the landscape. Biol Conserv. 1990;54(3):209-22.

13. Glista DJ, DeVault TL, DeWoody JA. A review of mitigation measures for reducing wildlife mortality on roadways. Landsc Urban Plan. 2009;91(1):1-7.

14. Charney ND, Letcher BH, Haro A, Warren PS. Terrestrial passive integrated transponder antennae for tracking small animal movements. J Wild Manag. 2009;73(7):1245-50.

15. Kissling WD, Pattemore DE, Hagen M. Challenges and prospects in the telemetry of insects. Biol Rev. 2014;89(3):511-30.

16. Baxter-Gilbert JH, Riley JL, Lesbarrères D, Litzgus JD. Mitigating reptile road mortality: fence failures compromise ecopassage effectiveness. PLoS ONE. 2015;10(3):e0120537.

17. Jumeau J. Les possibilités de dispersion et éléments d'habitat-refuge dans un paysage d'agriculture intensive fragmenté par un réseau routier dense: le cas de la petite faune dans la plaine du Bas-Rhin [PhD Thesis]. Strasbourg; 2017

18. Welbourne DJ, Paull DJ, Claridge AW, Ford F. A frontier in the use of camera traps: surveying terrestrial squamate assemblages. Remote Sens Ecol Conserv. 2017;3(3):133-45.

19. Hobbs MT, Brehme CS. An improved camera trap for amphibians, reptiles, small mammals, and large invertebrates. PLoS ONE. 2017; 12(10):e0185026.

20. Jarvis LE, Hartup M, Petrovan SO. Road mitigation using tunnels and fences promotes site connectivity and population expansion for a protected amphibian. Eur J Wildl Res. 2019;65(2):27.

21. Petrovan SO, Schmidt BR. Neglected juveniles; a call for integrating all amphibian life stages in assessments of mitigation success (and how to do it). Biol Conserv. 2019;1(236):252-60.

22. Eggert C. Use of fluorescent pigments and implantable transmitters to track a fossorial toad (Pelobates fuscus). Herpetol J. 2002;12(2):69-74. 
23. Matos C, Petrovan SO, Wheeler PM, Ward Al. Short-term movements and behaviour govern the use of road mitigation measures by a protected amphibian. Anim Conserv. 2019;22(3):285-96.

24. Matthews KR, Preisler HK. Site fidelity of the declining amphibian Rana sierrae (Sierra Nevada yellow-legged frog). Can J Fish Aquat Sci. 2010;67(2):243-55.

25. Ott JA, Scott DE. Effects of toe-clipping and PIT-tagging on growth and survival in metamorphic Ambystoma opacum. J Herpetol. 1999;33(2):344-8.

26. Perret $\mathrm{N}$, Joly P. Impacts of tattooing and PIT-tagging on survival and fecundity in the Alpine newt (Triturus alpestris). Herpetologica. 2002;1(58):131-8.

27. O'Neal ME, Landis DA, Rothwell E, Kempel L, Reinhard D. Tracking insects with harmonic radar: a case study. Am Entomol. 2004;50(4):212-8.

28. Vinatier F, Chailleux A, Duyck P-F, Salmon F, Lescourret F, Tixier P. Radiotelemetry unravels movements of a walking insect species in heterogeneous environments. Anim Behav. 2010;80(2):221-9.

29. Zydlewski GB, Horton G, Dubreuil T, Letcher B, Casey S, Zydlewski J. Remote monitoring of fish in small streams. Fisheries. 2006;31(10):492-502.

30. Gruber B. Measuring activity of geckos with an automatic movement monitoring system. Herpetol Rev. 2004;35(3):245.

31. Godsall B, Coulson T, Malo AF. From physiology to space use: energy reserves and androgenization explain home-range size variation in a woodland rodent. J Anim Ecol. 2014;83(1):126-35.

32. Harper SJ, Batzli GO. Monitoring use of runways by voles with passive integrated transponders. J Mammal. 1996;77(2):364-9.

33. Lucas MC, Mercer T, Armstrong JD, McGinty S, Rycroft P. Use of a flat-bed passive integrated transponder antenna array to study the migration and behaviour of lowland river fishes at a fish pass. Fish Res. 1999;44(2):183-91.

34. Prentice E. PIT-tag monitoring systems for hydroelectric dams and fish hatcheries. In: American fisheries society symposium. 1990. p. 323-34

35. Boarman WL, Beigel ML, Goodlett GC, Sazaki M. A passive integrated transponder system for tracking animal movements. Wildl Soc Bull. 1998;26:886-91.

36. Turin H. De Nederlandse loopkevers: verspreiding en oecologie (Coleoptera: Carabidae). In: Nationaal natuurhistorish museum, editor. Leiden, Pays-Bas: Nationaal Natuurhistorisch Museum; 2000.

37. Weber F, Heimbach U. Behavioural, reproductive and developmental seasonality in Carabus auronitens and Carabus nemoralis (Col., Carabidae). Mitteilungen Aus Biol Bundesanst Für Land-Forstwirtsch. 2001;382:1-194.
38. Hûrka K. Carabidae of the Czech and Slovak Republics. Zlin: Ing. Vit Kabourek; 1996

39. Riecken $U$, Raths $U$. Use of radio telemetry for studying dispersal and habitat use of Carabus coriaceus L. In: Annales Zoologici Fennici. JSTOR; 1996. p. 109-116.

40. Ribera I, Dolédec S, Downie IS, Foster GN. Effect of land disturbance and stress on species traits of ground beetle assemblages. Ecology. 2001;82(4):1112-29.

41. Vergnes A, Chantepie S, Robert A, Clergeau P. Are urban green spaces suitable for woodland carabids? First insights from a short-term experiment. J Insect Conserv. 2013;17(4):671-9.

42. Pagnucco KS, Paszkowski CA, Scrimgeour GJ. Characterizing movement patterns and spatio-temporal use of under-road tunnels by longtoed salamanders in Waterton Lakes National Park, Canada. Copeia. 2012;2012(2):331-40.

43. Collett RA, Fisher DO. Time-lapse camera trapping as an alternative to pitfall trapping for estimating activity of leaf litter arthropods. Ecol Evol. 2017;7(18):7527-33.

44. Jehle R, Hodl W. Pits versus patterns: effects of transponders on recapture rate and body condition of Danube crested newts (Triturus dobrogicus) and common spadefoot toads (Pelobates fuscus). Herpetol J. 1998;8:181-6.

45. Schulte U, Küsters D, Steinfartz S. A PIT tag based analysis of annual movement patterns of adult fire salamanders (Salamandra salamandra) in a Middle European habitat. Amphib-Reptil. 2007;28(4):531-6.

46. Christy M. The efficacy of using Passive Integrated Transponder (PIT) tags without anaesthetic in free-living frogs. Aust Zool. 1996;30(2):139-42.

47. Clevenger AP, Waltho N. factors influencing the effectiveness of wildlife underpasses in Banff National Park, Alberta, Canada. Conserv Biol. 2000;14(1):47-56

48. Yanes M, Velasco JM, Suarez F. Permeability of roads and railways to vertebrates: the importance of culverts. Biol Conserv. 1995;71(3):217-22.

49. Pomezanski $D$, Bennett $L$. Developing recommendations for monitoring wildlife underpass usage using trail cameras. Environ Monit Assess. 2018;190(7):413.

\section{Publisher's Note}

Springer Nature remains neutral with regard to jurisdictional claims in published maps and institutional affiliations.
Ready to submit your research? Choose BMC and benefit from:

- fast, convenient online submission

- thorough peer review by experienced researchers in your field

- rapid publication on acceptance

- support for research data, including large and complex data types

- gold Open Access which fosters wider collaboration and increased citations

- maximum visibility for your research: over $100 \mathrm{M}$ website views per year

At BMC, research is always in progress.

Learn more biomedcentral.com/submissions 